Article

\title{
Cymbopogon Citratus Functionalized Green Synthesis of CuO-Nanoparticles: Novel Prospects as Antibacterial and Antibiofilm Agents
}

\author{
Tijo Cherian ${ }^{1}$, Khursheed Ali ${ }^{1}$, Quaiser Saquib ${ }^{2, *}$, Mohammad Faisal ${ }^{3}{ }^{\mathbb{E}}$, Rizwan Wahab ${ }^{2}$ and \\ Javed Musarrat ${ }^{1,4}$ \\ 1 Faculty of Agricultural Sciences, Department of Agricultural Microbiology, Aligarh Muslim University, \\ Uttar Pradesh, Aligarh 202002, India; tvarghese891@gmail.com (T.C.); khursheedamu@gmail.com (K.A.); \\ musarratj1@yahoo.com (J.M.) \\ 2 Zoology Department, College of Sciences, King Saud University, P.O. Box 2455, Riyadh 11451, Saudi Arabia; \\ rizwannano@gmail.com \\ 3 Department of Botany \& Microbiology, College of Sciences, King Saud University, P.O. Box 2455, \\ Riyadh 11451, Saudi Arabia; faisalm15@yahoo.com \\ 4 School of Biosciences and Biotechnology, Baba Ghulam Shah Badshah University, Rajouri 185234, Jammu \& \\ Kashmir, India \\ * Correspondence: quaiser.saquib0@gmail.com or qsaquib@ksu.edu.sa
}

Received: 31 December 2019; Accepted: 20 January 2020; Published: 22 January 2020

\begin{abstract}
Chemically synthesized copper oxide nanoparticles (CuONPs) involve the generation of toxic products, which narrowed its biological application. Hence, we have developed a one-pot, green method for $\mathrm{CuONP}$ production employing the leaf extract of Cymbopogon citratus (CLE). Gas chromatography-mass spectrometry (GC-MS) analysis confirmed the capping of CuONPs by CLE esters (CLE-CuONPs). Fourier-transform infrared (FTIR) showed phenolics, sugars, and proteins mediated nucleation and stability of CLE-CuONPs. X-ray diffraction (XRD) and transmission electron microscopy (TEM) revealed CLE-CuONPs between 11.4 to $14.5 \mathrm{~nm}$. Staphylococcus aureus-1 (MRSA-1), Staphylococcus aureus-2 (MSSA-2) exposed to CLE-CuONPs $(1500 \mu \mathrm{g} / \mathrm{mL})$ showed 51.4\%, 32.41\% survival, while Escherichia coli-336 (E. coli-336) exposed to $1000 \mu \mathrm{g} / \mathrm{mL}$ CLE-CuONPs showed $45.27 \%$ survival. Scanning electron microscopy (SEM) of CLE-CuONPs treated E. coli-336, MSSA-2 and MRSA-1 showed morphological deformations. The biofilm production by E. coli-336 and MRSA-1 also declined to $33.0 \pm 3.2 \%$ and $49.0 \pm 3.1 \%$ at $2000 \mu \mathrm{g} / \mathrm{mL}$ of CLE-CuONPs. Atomic absorption spectroscopy (AAS) showed $22.80 \pm 2.6 \%, 19.2 \pm 4.2 \%$, and $16.2 \pm 3.6 \%$ accumulation of $\mathrm{Cu}^{2+}$ in E. coli-336, MSSA-2, and MRSA-1. Overall, the data exhibited excellent antibacterial and antibiofilm efficacies of esters functionalized CLE-CuONPs, indicating its putative application as a novel nano-antibiotic against multi drug resistance (MDR) pathogenic clinical isolates.
\end{abstract}

Keywords: Cymbopogon citratus; copper oxide nanoparticles; esters functionalization; antibiofilm; gas chromatography-mass spectrometry

\section{Introduction}

The popular choice for nanoparticles (NPs) synthesis include the chemical and physical methods. However, the utilization of toxic chemicals in the above processes narrowed their wider applications. Consequently, the green method was developed for the synthesis of NPs using the biological approach. In this context, the manipulation of nucleation and growth stages of NPs synthesis deserves special attention because it helped the nanotechnologists to produce varying types of NPs [1]. Therefore, 
researchers have shown enormous interest towards the synthesis of inorganic and organic NPs [2,3], enabling them to be used in a range of biomedical settings [4,5].

The capping agents, reducing agents, as well as the reaction solvents were considered important for the NPs synthesis via the green approach. Particularly, the crude leaf extracts from different plants showed the presence of bio-active molecules including the proteins [6], polysaccharides [7], polyphenols [8], terpenoids [9], and esters [10]. These agents played an important role as reducing and capping entities in the synthesis of metallic NPs.

The metal oxide NPs, owing to their fascinating physicochemical characteristics of transition, have received considerable attention in the field of nanotechnology. Amongst such metal oxides, copper oxide $(\mathrm{CuO})$ is a p-type semiconductor with a narrow band gap of 1.2-1.7 eV. $\mathrm{CuO}$ is widely acclaimed for its photoconduction relevance, fabrication of various electro-optics devices [11-13], high temperature conductive superconductors [14], and gas sensors [15]. The crystalline monoclinic structures of CuONPs have engrossed great usability in a range of scientific and technical applications [16]. The applicability of CuONPs as antimicrobials [17], pesticidal formulations [18], dye photo-degradation [19], drug delivery and imaging agent has revolutionized the field of medico-diagnostics. CuONPs have also been explored as an efficient recyclable catalyst $[20,21]$. Traditionally, CuONPs have been synthesized by the physical and chemical methods, including solid state thermal decomposition [22], chemical precipitation [23], sol gel [24], and pulsed wire explosion methods [25]. All methods do have a common drawback to generate toxic products, which are incongruous for the biological utilization. As a safer alternative, the biological schemes employing plants leaf extracts superseded the chemical methods $[9,10,13]$.

Cymbopogon citratus (CLE) is an aromatic plant belonging to the family Gramineae [26]. The active phytochemicals present in CLE are long chain hydrocarbons, alcohols, ketones, esters, and aldehydes. Essential oil mainly consists of terpenes and triterpenoids. Major flavonoids include luteolin and its 6-C and 7-O-glycosides, isoorientin 2'-O-rhamnoside, quercetin, kaempferol, and apigenin. The phenolic compounds in CLE were primarily found to be elimicin, catecol, chlorogenic acid, caffeic acid, and hydroquinone [26]. Studies have indicated the successful use of Cymbopogon extracts for the fabrication of metallic NPs like silver, gold, copper, cerium dioxide, which have demonstrated their antibiosis and dye degradation benefits [27-30]. The large applications of CuONPs, as well as the bio-actives of CLE, have led us to scrutinize the crude aqueous extract of CLE as a reducing, capping and stabilizing agent for the bio-synthesis of CLE-CuONPs. To the best of our knowledge, until now, there is no comprehensive and systematic report available, which has demonstrated that the three bio-active esters of CLE (dipropyleneglycol-1 diacrylate $\left(\mathrm{C}_{12} \mathrm{H}_{18} \mathrm{O}_{5}\right)$, $\alpha$-monoolein $\left(\mathrm{C}_{21} \mathrm{H}_{40} \mathrm{O}_{4}\right)$, and Isooctyl phthalate $\left(\mathrm{C}_{24} \mathrm{H}_{38} \mathrm{O}_{4}\right)$ actively reduce $\mathrm{Cu}^{2+}$ to $\mathrm{CuONPs}$. The present work is novel, and the first of its kind on CLE-CuONPs, demonstrating its antibacterial and antibiofilm efficacies against multi drug resistance (MDR) clinical isolates. Hence, this study aimed to (i) optimize the synthesis of CuONPs using CLE extracts, (ii) characterization of biogenically synthesized CLE-CuONPs, (iii) analysis of bio-active compounds of CLE-CuONPs, and (iv) antibacterial and antibiofilm potential of CLE-CuONPs against clinical isolates.

\section{Materials and Methods}

\subsection{Chemicals and Bacterial Strains}

Copper sulphate $\left(\mathrm{CuSO}_{4} \cdot 5 \mathrm{H}_{2} \mathrm{O}\right)$, hydrochloric acid $(\mathrm{HCl})$, sodium hydroxide $(\mathrm{NaOH})$ were of highest analytical grade purchased from Hi-media, Pvt. Ltd. Mumbai, India. Glassware were procured from Borosil, India. Before experiments, all glassware was treated with $1 \mathrm{~N} \mathrm{H}_{2} \mathrm{SO}_{4}$, and thoroughly washed with tap water followed by rewashing with deionized ultrapure water (TKA Genpure, Niederelbert, Rheinland-Pfalz, Germany). The Gram-positive methicillin-resistant Staphylococcus aureus-1 (MRSA-1), methicillin-sensitive Staphylococcus aureus-2 (MSSA-2), and Gram-negative extended spectrum $\beta$-lactamases (ES $\beta L$ ) producing Escherichia coli-336 (E. coli-336) clinical isolates was a kind gift from the Department of Microbiology, Jawaharlal Nehru Medical College, Aligarh Muslim University, 
Aligarh, India. After the in-house validation, the clinical isolates were sub-cultured in Luria-Bertani (LB) culture medium (Hi-media, Pvt. Ltd. Mumbai, India) at $37^{\circ} \mathrm{C}$ in a shaker (180 rpm) for overnight, and stored at $-20^{\circ} \mathrm{C}$ in $20 \%$ glycerol for long-term preservation.

\subsection{Preparation of Cymbopogon Citratus (CLE) Extract}

The preparation of Cymbopogon citratus leaves extract (CLE) were carried out by following our earlier described procedure [10]. Precisely, $50 \mathrm{~g}$ green leaves were collected from forest cover range at Kottayam district $\left(9.4710933^{\circ} \mathrm{N}, 76.7650384^{\circ} \mathrm{E}\right)$ Kerala, India. Sample identification was done by taxonomist in the Department of Botany, Aligarh Muslim University, India. The leaves were washed with ultrapure water Milli Q (MQ) water thoroughly and minced to fine green paste by the use of mixer grinder. Paste was then added to $100 \mathrm{~mL}$ of water, and kept for $20 \mathrm{~min}$ at ambient temperature. The liquid extract of CLE was then filtered through Whatman paper No.1 and stored at $-20{ }^{\circ} \mathrm{C}$ till further use.

\subsection{Synthesis Optimization and Characterization of CLE-CuO NPS}

Synthesis and optimization of CLE-CuONPs yield were investigated by the previously described method [9]. Briefly, CLE-CuONPs formation was assessed under the steady elevation of CLE concentrations $(10,20,30,40$ and 50\%) and different $\mathrm{pH}(4.0,6.0,8.010 .0$ and 12.0), while keeping the $\mathrm{CuSO}_{4}$ concentration constant $(0.25 \mathrm{mM})$. $\mathrm{pH}$ adjustment was done by enriching the reaction mixtures with $0.1 \mathrm{M} \mathrm{HCl}$ and $\mathrm{NaOH}$. The suspensions were kept at $60{ }^{\circ} \mathrm{C}$ for $3 \mathrm{~h}$ under constant stirring. A dry greyish black powder of CLE-CuONPs was finally obtained by centrifugation at $3000 \mathrm{rpm}$ for $5 \mathrm{~min}$, followed by vacuum filtration, and drying for $4 \mathrm{~h}$ at $80{ }^{\circ} \mathrm{C}$. The physicochemical properties of CLE-CuONPs were determined using the following techniques. Surface plasmon resonance (SPR) of CLE-CuONPs was recorded by the use of double beam UV-Vis spectrophotometer (Cintra 101, GBC Scientific Equipment Ltd., Dandenong, VIC, Australia) in the range of 540-660 nm. SPR peaks at different percentages of CLE and $\mathrm{pH}$ were recorded. For the blank, ultrapure water water was used. Background absorption was subtracted from the reading of CLE [9]. Powdered sample of CLE-CuONPs was used for the X-ray diffraction (XRD) patterns (Rigaku Corporation, Tokyo, Japan) at $40 \mathrm{kV}, 30 \mathrm{~mA}$ current, and $\mathrm{CuK} \alpha$ radiation $(\mathrm{k}=1.54 \AA)$. Intensities were recorded between $20-80^{\circ} 2 \theta$ angles. CLE-CuONPs size and crystalline phase purity were calculated using the Debye-Scherrer's equation: $\mathrm{D}=0.9 \lambda / \beta \cos \theta$ [9]. Structural analysis of CLE-CuONPs was done using the scanning electron microscope (SEM) at $20 \mathrm{kV}$ (JEOL Ltd., Tokyo, Japan). Fine powder of CLE-CuONPs was placed on the carbon tape, followed by gold coating using vacuum sputter. The percentage of $\mathrm{C}, \mathrm{O}$ and $\mathrm{Cu}$ elements in CLE-CuONPs was analyzed using energy dispersive X-ray (EDS) spectrum (Oxford Instruments INCA x-sight, Concord, MA, USA) [9]. CLE-CuONPs was further characterized using the transmission electron microscope (TEM) (JEOL, Tokyo, Japan) at an accelerating voltage of $200 \mathrm{kV}$. Samples were prepared by dispensing $10 \mu \mathrm{L}$ of CLE-CuONPs on to the $\mathrm{Cu}$ grid, and the liquid was vacuum dried $\left(80^{\circ} \mathrm{C}, 6 \mathrm{~h}\right)[9]$.

\subsection{GC-MS and FTIR Analyses of CLE-CuONPS}

GC-MS analysis of CLE and colloidal CLE-CuONPs solution was performed on GC-MS (GC-7890A, Agilent Technologies, Santa Clara, CA, USA) equipped with paraphernalia such as silica capillary column (30 m length, $0.25 \mathrm{~mm}$ inner diameter, $0.25 \mu \mathrm{m}$ film thickness), a triple-axis detector, and oven $\left(60-325^{\circ} \mathrm{C}\right.$ at $5^{\circ} \mathrm{C} / \mathrm{min}$ for $\left.5 \mathrm{~min}\right)$. The inlet and interface temperatures were set as $280{ }^{\circ} \mathrm{C}$ and $325^{\circ} \mathrm{C}$, respectively. Helium $(\mathrm{He})$ was used as carrier at $1.0 \mathrm{~mL} / \mathrm{min}$ flow rate. In addition, $1 \mu \mathrm{L}$ of the sample was injected under a split of 20:1. EIMS: electron energy, $70 \mathrm{eV}$. The MS data were deciphered using 62,000 patterns compiled as an NIST database library [9]. Similarly, in order to confirm CLE bio-actives capping on NPs, CLE alone and CLE-CuONPs were analyzed by Fourier-transform infrared (FTIR) (Perkin Elmer, Shelton, CT, USA). For FTIR, CLE and CLE-CuONPs were separately mixed with 
spectroscopic grade of $\mathrm{KBr}$ in a ratio of 1:100, followed by the recording of spectra at a resolution of $4 \mathrm{~cm}^{-1}$ [31].

\subsection{Antibacterial Activities}

\subsubsection{Well Diffusion Assay, MIC, and MBC Determinations}

The antibacterial activities of CLE-CuONPs were assessed by a well diffusion assay following our previously described method [31]. Briefly, the overnight grown cultures of E. coli-336, MRSA-1, and MSSA-2 $\left(\mathrm{OD}_{600}=0.1 \sim 10^{7}\right.$ colony forming unit $\left.(\mathrm{CFU}) / \mathrm{mL}\right)$ were used for the study. Cultures were spread on LB agar plates, wells of $6 \mathrm{~mm}$ diameter were cut and filled with CLE alone (as control), and varying concentrations of CLE-CuONPs $(500,1000,1500$ and $2000 \mu \mathrm{g} / \mathrm{mL})$ were added in respective wells. All plates were then incubated for $24 \mathrm{~h}$ at $37^{\circ} \mathrm{C}$ followed by the analysis of zone of inhibition [31]. For the minimum inhibitory concentration (MIC) and minimum bactericidal concentrations (MBC), the overnight grown bacterial cultures $\left(\sim 10^{7} \mathrm{CFU} / \mathrm{mL}\right)$ in liquid LB media containing 500, 1000, 1500, 2000, 2500 and $3000 \mu \mathrm{g} / \mathrm{mL}$ of CLE-CuONPs were incubated for $24 \mathrm{~h}$ at $37^{\circ} \mathrm{C}$. An aliquot of $100 \mu \mathrm{L}$ from the cultures was spread on LB agar plates, followed by incubating the plates at $37^{\circ} \mathrm{C}$ for $24 \mathrm{~h}$. MIC and MBC were determined based on the colony forming ability of the test strains.

\subsubsection{Effect of CLE-CuONPs on Growth and Viability of Bacteria}

The growth and viability tests were performed according to our previously described method [31]. In brief, $20 \mu \mathrm{L}$ of overnight grown cultures E. coli-336, MRSA-1 and MSSA-2 were seeded into 96-wells of microtiter plates. LB medium containing fixed volume (300 $\mu \mathrm{L})$ of CLE-CuONPs 125, 250, 500, 1000 , and $2000 \mu \mathrm{g} / \mathrm{mL}$ were added to the respective wells. Untreated bacteria were used as control in all experiments. At the time intervals of $2 \mathrm{~h}$, changes in the optical density was recorded at $620 \mathrm{~nm}$ $\left(\mathrm{OD}_{620} \mathrm{~nm}\right)$ using a microplate reader (Thermo Scientific Multiskan, China). The percent viability was also estimated by comparing the $\mathrm{OD}_{620} \mathrm{~nm}$ of CLE-CuONPs treated bacterial cultures with untreated control experiments after $24 \mathrm{~h}$.

\subsubsection{SEM Imaging of Bacteria and NPs Interaction}

Morphological changes in the bacterial cells were done by following our previously described method [10]. In brief, E. coli-336 and MRSA-1 cells were treated with CLE-CuONPs $(1000 \mu \mathrm{g} / \mathrm{mL})$ for $24 \mathrm{~h}$ at $37^{\circ} \mathrm{C}$. Under the similar condition, E. coli-336 and MRSA-1 not exposed to CLE-CuONPs were taken as control. After the incubation, the bacterial cells were spun at $3000 \mathrm{rpm}$ for $5 \mathrm{~min}$, and placed in $2.5 \%$ glutaraldehyde solution for $4 \mathrm{~h}$. Bacterial cells were dehydrated in an ascending series of 30 , 50, 70 and 90 and 100\% ethanol. Finally, $100 \mu \mathrm{L}$ bacterial cells were evenly spread on the clean glass cover, and deposited on SEM stub after sputter coated with gold-palladium. Morphological analysis was done at $15 \mathrm{kV}$.

\subsubsection{Intracellular Uptake of CLE-CuONPs}

The uptake of CLE-CuONPs in bacterial cells were analyzed by our previously described method [9]. Quantitative estimation was done employing the atomic absorption spectroscopy (AAS) of E. coli-336, MSSA-2, and MRSA-1 grown for $24 \mathrm{~h}$ in the presence of CLE-CuONPs (1000 $\mu \mathrm{g} / \mathrm{mL})$. Under the identical conditions, a separate set of above strains were grown without CLE-CuONPs, which were taken as control cells. After $24 \mathrm{~h}$, the bacterial cells were spun down at $3000 \mathrm{rpm}$ for $15 \mathrm{~min}$. Washing of pellets were done twice to remove surface bound NPs. Pellets were then subjected to digestion in aqua regia $\left(\mathrm{HNO}_{3}: \mathrm{HCl}=1: 3 \mathrm{v} / \mathrm{v}\right)$ at $60{ }^{\circ} \mathrm{C}$. The digests were diluted to $100 \mathrm{~mL}$ in ultrapure deionized water, and finally analyzed on a double beam AAS (GBC Model 932B plus, GBC Scientific Equipment Ltd., Dandenong, VIC, Australia). The amount of internalized CLE-CuONPs was quantified by comparing the concentration of $\mathrm{Cu}^{2+}$ in the treated cells, with the amount of treatment concentration $(1000 \mu \mathrm{g} / \mathrm{mL})$. In parallel, the internalization propensity of CLE-CuONPs was qualitatively evaluated 
on TEM following our previous method [9]. E. coli-336 and MRSA-1 were treated with CLE-CuONPs $(500-1000 \mu \mathrm{g} / \mathrm{mL})$ for $24 \mathrm{~h}$ at $37^{\circ} \mathrm{C}$. Under the similar conditions, E. coli-336 and MRSA-1 grown without CLE-CuONPs were taken as control. After $24 \mathrm{~h}$, cells were centrifuged at $3000 \mathrm{rpm}$ for $15 \mathrm{~min}$ and washed twice. Bacterial cells were fixed using glutaraldehyde (2.5\%), osmium tetraoxide (1\%), and then embedded in Epon resin (Polybed 812). Ultra-thin sections were prepared, and staining was done using uranyl acetate and lead citrate (Sigma Aldrich, St. Louis, MO, USA). Image analysis was done on TEM (100/120 kV) [9].

\subsubsection{Effect of CLE-CuONPs on Bacterial Biofilm}

Antibiofilm efficacy of CLE-CuONPs were evaluated against the three test strains by standard crystal violet (CV) assay, as described in our earlier study [9]. Precisely, $100 \mu \mathrm{L}$ of E. coli-336, MSSA-2, and MRSA-1 grown for overnight in LB culture medium $\left(\sim 10^{7}\right.$ cells $\left./ \mathrm{mL}\right)$ were seeded into 96-wells of microtiter plate (Corning, NY, USA). A fixed volume $(200 \mu \mathrm{L})$ of culture medium, containing varying concentrations $(125-2000 \mu \mathrm{g} / \mathrm{mL})$ of CLE-CuONPs were added to the respective wells. Untreated bacterial cells in LB culture medium were used as parallel positive controls. Plates were allowed to dry at $37^{\circ} \mathrm{C}$ for $24 \mathrm{~h}$. The loosely adhered cell suspensions were removed by washing with autoclaved phosphate buffer saline (PBS). All wells were then dispensed with $200 \mu \mathrm{L}$ of CV solution (0.25\%), and incubated for $30 \mathrm{~min}$ at $37^{\circ} \mathrm{C}$. The unbound $\mathrm{CV}$ were washed, and wells were dried at room temperature. CV bounded to the bacterial cells were finally dissolved in $200 \mu \mathrm{L}$ of ethanol (95\%), and the absorbance was read at $\mathrm{OD}_{620 \mathrm{~nm}}$ on a microplate reader. Additionally, CLE-CuONPs induced biofilm eradication was also investigated by confocal laser scanning microscopy (CLSM), following our previously described method [9]. Briefly, E. coli-336 and MRSA-1 were grown on glass cover, and treated with sub-lethal concentrations of CLE-CuONPs (500 and $1000 \mu \mathrm{g} / \mathrm{mL}$ ) for $24 \mathrm{~h}$. The biofilms adhered on the glass cover were first immersed in PBS to remove the planktonic cells, and then in $1 \mu \mathrm{M}$ concanavalin-A-fluorescein isothiocyanate (Con-A FITC). Con-A FITC binds specifically to sugars, glycoproteins, and glycolipids accumulated in the extracellular polysaccharides (EPS) layers around the bacterial cells. The reduction in the biofilm was visualized by change in the fluorescence intensity of Con-A FITC (488-530 nm) on CLSM (Leica TCS SP5, Leica Microsystems, Mannheim, Germany) [9].

\subsection{Statistics}

The statistical analyses were done on Sigma Plot 11.0 (Sigma Plot 11.0, Systat Software, Inc., San Jose, CA, USA). A Holm-Sidak test for multiple comparisons versus a control group was used for one-way analysis of variance (ANOVA). The data were expressed as mean \pm SD of at least three independent experiments done in triplicate. The differences were considered statistically significant if ${ }^{*} p<0.05$ unless otherwise stated.

\section{Results and Discussion}

\subsection{Synthesis and Optimization of CLE-CuONPS}

The yield of bio-inspired CLE-CuONPs was assessed by monitoring the characteristic UV-visible absorbance band in the range of 540-650 nm under varied concentrations of CLE (10, 20, 30, 40, and $50 \% v / v)$, and $\mathrm{pH}(4.0,6.0,8.0,10.0$, and 12.0) of the reaction mixture. After $3 \mathrm{~h}$ of CLE exposure to $\mathrm{CuSO}_{4}$ at $60{ }^{\circ} \mathrm{C}, \mathrm{CLE}-\mathrm{CuONPs}$ formation was marked with the change of reaction mixture color from green to greyish black (Figure 1). Such change has been related with the excitation of SPR or inter-band transitions, thus reflecting the metallic nature of NPs [32]. The CLE-CuONPs SPR peak at $574 \mathrm{~nm}$ was very close to an SPR peak of ascorbic acid-CuONPs at $550 \mathrm{~nm}$ [33]. We have observed a hypochromic shift (i.e., a decrease in absorption from 9.3 to 8.2) in SPR at $574 \mathrm{~nm}$ upon increasing CLE concentration from 10 to $50 \%$, while the concentration of $\mathrm{CuSO}_{4}$ throughout the reaction was fixed at $0.25 \mathrm{mM}$. This hypochromic shift in SPR peak indicates the reduction in NP size [34], which highlights the fact that an increase in CLE bio-actives enhanced the $\mathrm{Cu}^{2+}$ reduction, nucleation, and capping kinetics, 
respectively (Figure 2A). In case of $\mathrm{pH}$ manipulation, while keeping the CLE $(10 \%)$ and $\mathrm{CuSO}_{4}(0.25 \mathrm{mM})$ concentrations fixed (Figure 2B), the UV-vis spectra exhibited hyperchromic shift (i.e., an increase in SPR absorption as 6.0, 6.2, 7.4 and 9.2) reflecting an increase in the size of NPs at $\mathrm{pH} 4.0,6.0,8.0$, and 10.0, respectively. However, an increase in $\mathrm{pH}$ from 10.0 to 12.0 caused hypochromic shift in SPR peak, marking the optimum reduction of $\mathrm{Cu}^{2+}$ to CLE-CuONPs at $\mathrm{pH}$ 10.0. The stability of colloidal reaction mixture of CLE-CuONPs was measured using UV-Vis spectrophotometric measurments. The analysis showed peak at $574 \mathrm{~nm}$ for 6 months, further confirming the stability of synthesized NPs with no precipitation (Figure 2C). The rationale for CLE-CuONPs synthesis was based on the fact that $10 \%$ CLE and pH 10.0 showed significant long-term colloidal dispersion and stability. Such characteristics could be due to the soft corona of CLE bio-actives induced steric hindrance around the particles. These effects may reduce the aggregation of NPs due to the electrostatic interactions [9].

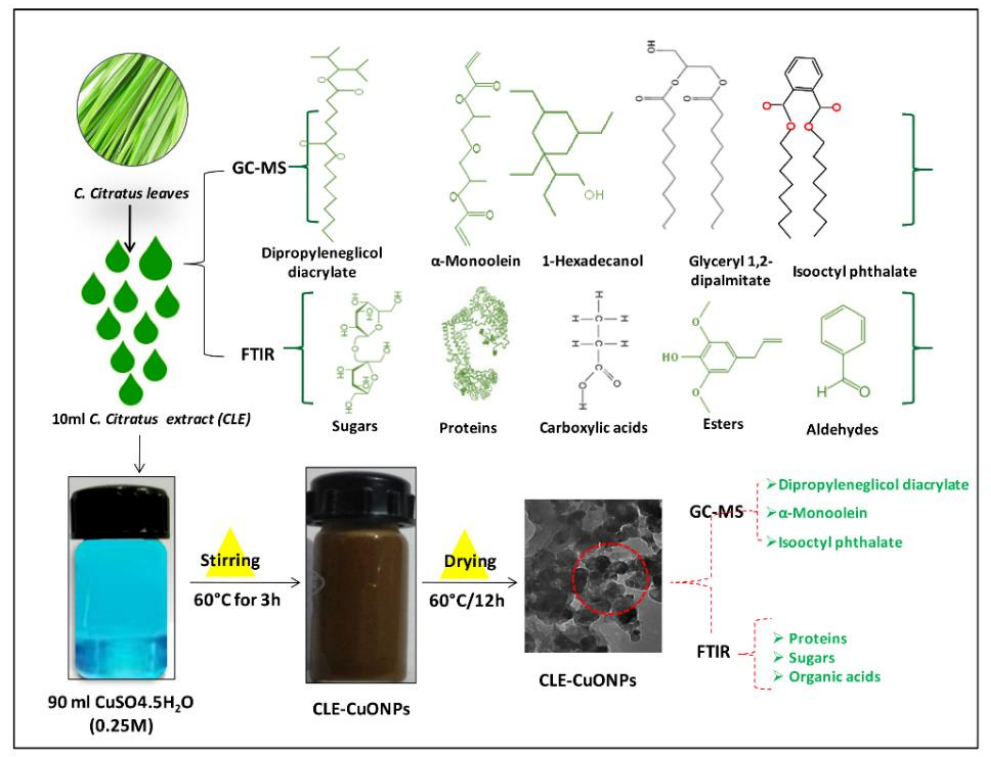

Figure 1. Graphical representation of CLE-CuONPs synthesis.
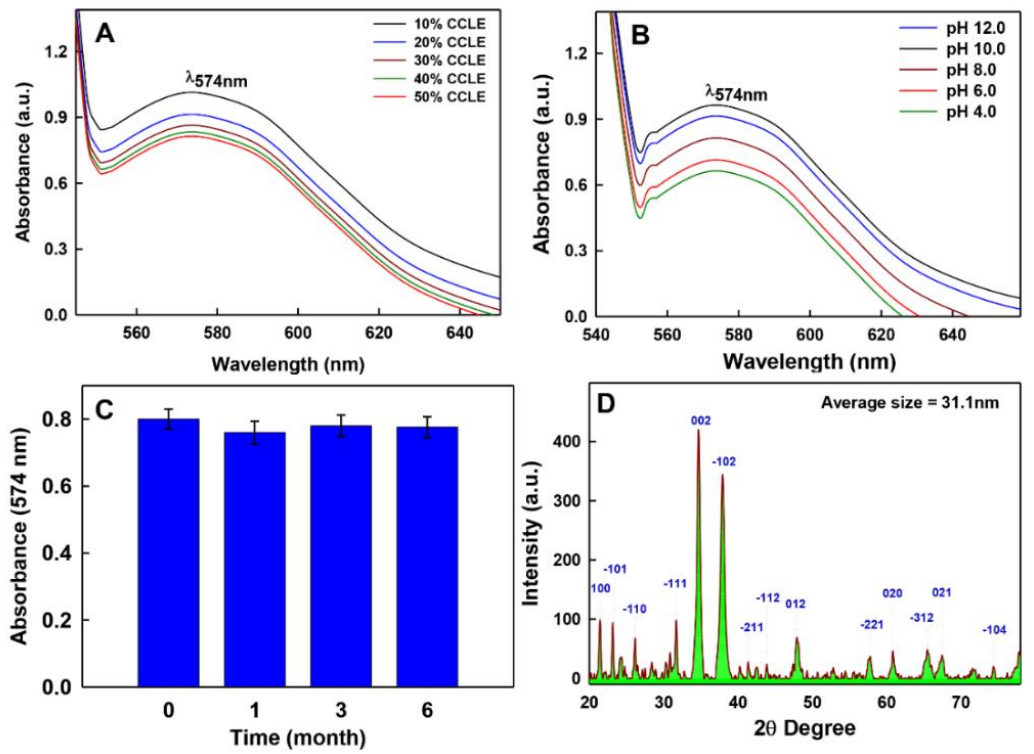

Figure 2. Physicochemical characterization of CLE-CuONPs. UV-Vis spectra-based optimization of CLE-CuONPs synthesis as a function of CLE concentration $(10,20,30,40$ and 50\%) (A), and pH (4.0, 6.0, 8.0, 10.0 and 12.0) (B) showing SPR peak at $~ 574 \mathrm{~nm}$. (C) shows the stability of CLE-CuONPs based on the SPR measurements up to six months (error bars represent the mean \pm SDSE of three replicates); (D) demonstrates X-ray diffraction (XRD) patterns of biologically synthesized CLE-CuONPs. 


\subsection{Morphology and Crystallinity of CLE-CUONPs}

The XRD data further suggested the crystalline nature of CLE-CuONPs prepared with 10\% CLE at $\mathrm{pH} 10.0$ (Figure 2D). The diffraction peaks obtained at $2 \theta$ values $32.69^{\circ}, 34.68^{\circ}, 37.87^{\circ}, 47.93^{\circ}, 57.88^{\circ}$, $60.87^{\circ}, 65.42^{\circ}, 67.45^{\circ}$, and $74.50^{\circ}$ corresponds to $110,002 /-111,111 / 200,112,021,-113,022,311$, and 004/-222 hkl lattice planes, respectively. The XRD peaks were readily indexed to the monoclinic symmetry of $\mathrm{CuO}$ with lattice constants $\mathrm{a}=4.684 \AA, \mathrm{b}=3.425 \AA \mathrm{c}=5.129 \AA$, and $\beta=99.47 \AA$ obtained by following the International Centre for Diffraction Data (ICDD, obtained from JCPDS 080-1268) [35]. The average crystal size of CLE-CuO-NPs was determined to be $31.1 \mathrm{~nm}$. In addition, the data obtained using the TEM and SEM analyses confirmed the morphology of NPs synthesized using aqueous CLE $(10 \%)$ at $\mathrm{pH} 10.0$. The TEM micrograph exhibits that CLE bio-actives significantly contributed in the bio-reduction of $\mathrm{Cu}^{2+}$ or $\mathrm{Cu}^{3+}$ into crystalline CLE-CuONPs (Figure 3A). The average crystal size of $14.5 \pm 2.0 \mathrm{~nm}$ (Figure 3B) was calculated by processing the TEM image of Figure 3A, employing the ImageJ multidimensional image processing software. It is also apparent that, with our optimal synthesis conditions, CLE bio-actives could configure nascent NPs into noticeable different morphologies as spherical, hexagonal and oval shapes (Figure 3A). In addition, varying NPs sizes (2 to $22 \mathrm{~nm}$ ) were generated, although the majority of NPs ranged between 12 to $14 \mathrm{~nm}$ (Figure 3B). On the other hand, the SEM image (Figure 3C) exhibits a bud or needle like morphology. The formation of needle-like $\mathrm{CuONPs}$ is a well observed phenomenon of the aggregation of small NPs, and monoclinic crystalline nature of $\mathrm{CuO}[36,37]$. EDS analysis further indicated the presence of elemental copper $(26.62 \%)$ and oxygen (43.62) in association with carbon (29.76\%) (Figure 3D), which can be assigned to the corona of CLE bio-actives moieties adsorbed onto the CuONPs.
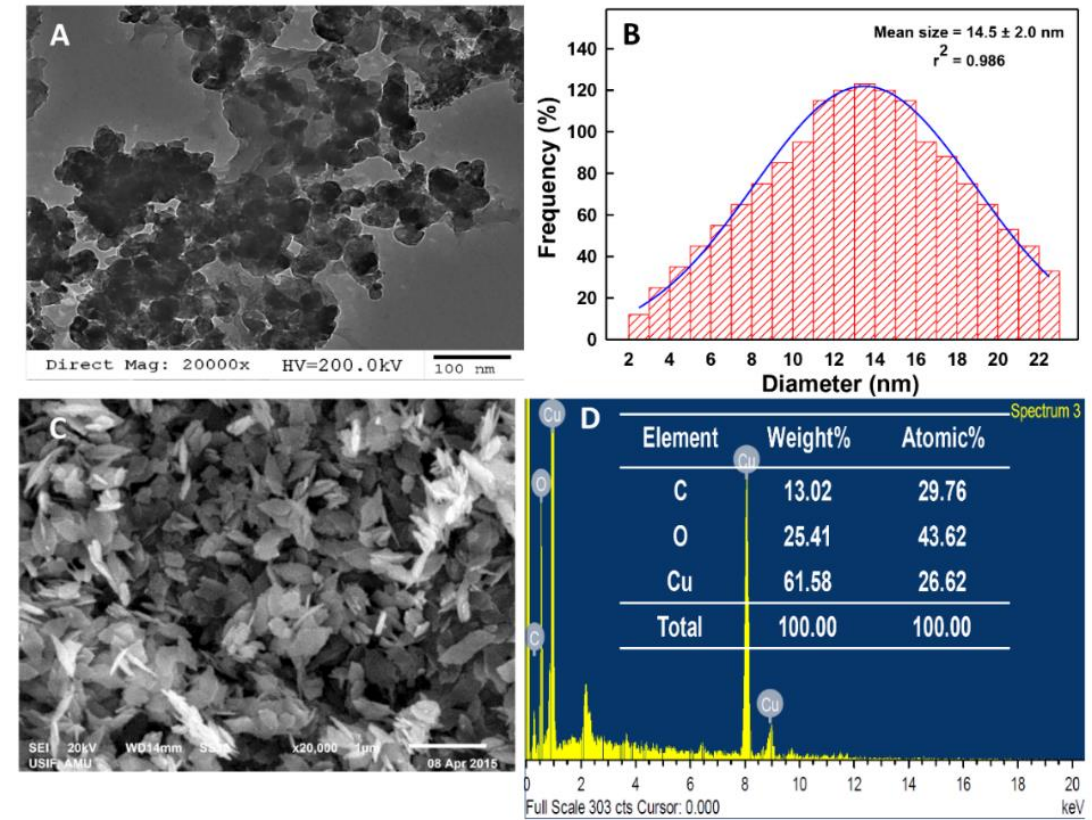

Figure 3. Electron microscopic analyses of CLE-CuONPs. (A) demonstrates TEM images of CLE-CuONPs; (B) depicts the particle size distribution in TEM images; (C) shows scanning electron microscope (SEM) micrographs of CLE-CuONPs and (D) is the energy dispersive X-ray (EDS) spectrum showing the percentage of $\mathrm{C}, \mathrm{O}$ and $\mathrm{Cu}$ elements in CLE-CuONPs.

\section{3. $\mathrm{Cu}^{2+}$ Reduction Mechanism}

The organic support of CLE bio-actives in the reduction of $\mathrm{Cu}^{2+}$ and capping of CuONPs was ascertained by comparing the FTIR spectrum of CLE-alone (Figure 4A(i)) and CLE-CuONPs (Figure 4A(ii)). The spectrum of CLE-CuONPs (Figure 4A(ii)) shows that the appearance of sharp bands at 3572, 3488 and $2926 \mathrm{~cm}^{-1}$ are likely due to stretching of $-\mathrm{OH},-\mathrm{NH}$ and $\mathrm{CHO}$ groups associated with the skeletons of CLE 
bio-actives [38]. Changes in the sharp peak at $1628 \mathrm{~cm}^{-1}$ in the CLE-CuONPs spectrum justify the role of $-\mathrm{C}=\mathrm{O}$ stretch of ester and amide groups in NP formation (Figure 4A(i,ii)) [39]. Similarly, the formation of a series of sharp peaks between 1152 and $611 \mathrm{~cm}^{-1}$ was described in Supplementary Data (Table S1). The peaks that were assigned to - $\mathrm{CN}$ and C-O-C groups indicate the viable role of protein moieties in the synthesis of NPs [40]. Importantly, the banding and stretching vibrations between 520 and $491 \mathrm{~cm}^{-1}$ are $^{-}$ typically known to reflect the signature of bonds between metal and oxygen [41]. In view of the reducing and ligation properties of esters in CLE, it can be articulated that the oxygenated functional groups of bio-actives orchestrated an energy-efficient reduction and nucleation of $\mathrm{Cu}^{2+}$ into $\mathrm{CuONPs}$.
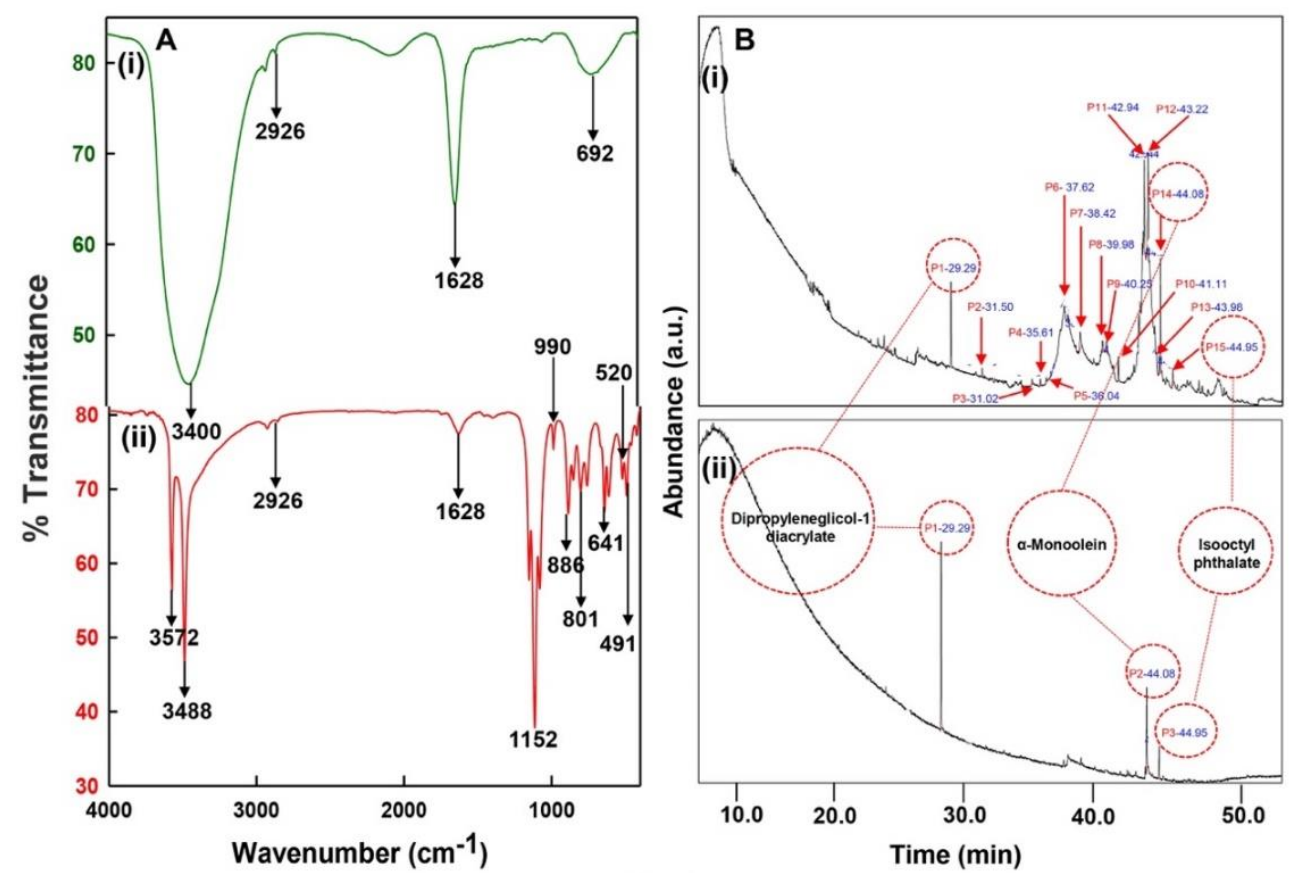

Figure 4. FTIR and GC-MS analyses of CLE and CLE-CuONPs. (A) comparison of FTIR spectra of CLE (spectrum-i) and CLE-CuONPs (spectrum-ii); (B) GC-MS analysis (spectrum-i) shows a typical chromatogram of CLE indicating 15 peaks of different bio-actives. Spectrum-ii shows three CLE compounds: dipropyleneglycol-1 diacrylate, $\alpha$-monoolein, and iso-octyl phthalate associated with CLE-CuONPs.

\subsection{GC-MS Analysis of CLE-CUONPs}

The GC-MS shows 15 different peaks (P1-P15) for 11 types of bio-actives esters (Figure 4B(i)) in aqueous extract of CLE (Table 1). The structure of esters is the association of cyclic/hemicyclic ring and a linear hydrocarbon molecule bearing various oxygenated functional groups (Table 1). Hence, it can be speculated that a single CLE ester may produce two or even multiple spectral signatures with different retention times and peak areas. The mass and charge ratio $(\mathrm{m} / \mathrm{z})$ of esters were used to identify the compound with NIST retention index library $[42,43]$. The heteroatom-functionalized long-chain hydrocarbons have been known to play important roles in controlling the morphology, size, and monodispersity of NPs. The presence of such bio-active hydrocarbons, aldehyde, and long chain fatty acids in CLE has also been evidenced in methanol extract of CLE leaves [44]. GC-MS analysis of CLE-CuONPs revealed the appearance of three bio-active esters including Dipropyleneglicol diacrylate (P1), $\alpha$-Monoolein (P2) and Isooctyl phthalate (P3) (Table 2). These bio-active esters reflect their plausible role in the reduction and nucleation of $\mathrm{Cu}^{2+}$ or $\mathrm{Cu}^{3+}$ into CLE-CuONPs (Table 1). Di-isooctyl phthalate has also been reported in the extract fractions of Limonium bicolour [45]. 
Table 1. GC-MS analysis of CLE leaf extract.

\begin{tabular}{|c|c|c|c|c|c|c|}
\hline Peaks (P) & Retention Time (RT) & Name of Compound & Mol. Wt. & Mol. Formula & Peak Area $(\%)$ & Structure \\
\hline 1 & 29.297 & Dipropyleneglicol diacrylate & 242.26 & $\mathrm{C}_{12} \mathrm{H}_{18} \mathrm{O}_{5}$ & 13.29 & \\
\hline 2 & 31.506 & 1-Hexadecanol & 242.44 & $\mathrm{C}_{16} \mathrm{H}_{34} \mathrm{O}$ & 1.383 & \\
\hline 3 & 35.023 & n-Hexadecenoic acid & 256.42 & $\mathrm{C}_{16} \mathrm{H}_{32} \mathrm{O}_{2}$ & 1.042 & \\
\hline 4 & 35.616 & 2-Tetradecanol & 214.38 & $\mathrm{C}_{14} \mathrm{H}_{30} \mathrm{O}$ & 0.972 & \\
\hline 5 & 36.04 & Dodecyl 3-mercaptopropanoate & 274.46 & $\mathrm{C}_{15} \mathrm{H}_{30} \mathrm{O}_{2} \mathrm{~S}$ & 1.264 & \\
\hline 6 & 37.621 & $\alpha, \gamma$-Dipalmitin & 296.48 & $\mathrm{C}_{19} \mathrm{H}_{36} \mathrm{O}_{2}$ & 1.886 & \\
\hline 7 & 38.426 & 13-Octadecenoic acid & 282.46 & $\mathrm{C}_{18} \mathrm{H}_{34} \mathrm{O}_{2}$ & 6.217 & \\
\hline 8 & 39.982 & Glyceryl 1,2-dipalmitate & 568.91 & $\mathrm{C}_{35} \mathrm{H}_{68} \mathrm{O}_{5}$ & 2.665 & \\
\hline 9 & 40.258 & Glyceryl 1,2-dipalmitate & 568.91 & $\mathrm{C}_{35} \mathrm{H}_{68} \mathrm{O}_{5}$ & 5.058 & \\
\hline 10 & 41.119 & Glyceryl 1,2-dipalmitate & 568.91 & $\mathrm{C}_{35} \mathrm{H}_{68} \mathrm{O}_{5}$ & 3.903 & \\
\hline 11 & 42.944 & $\alpha$-Monoolein & 356.53 & $\mathrm{C}_{21} \mathrm{H}_{40} \mathrm{O}_{4}$ & 16.534 & \\
\hline 12 & 43.22 & $\alpha$-Monoolein & 356.53 & $\mathrm{C}_{21} \mathrm{H}_{40} \mathrm{O}_{4}$ & 21.603 & \\
\hline
\end{tabular}


Table 1. Cont.

\begin{tabular}{lccccc}
\hline Peaks (P) & Retention Time (RT) & Name of Compound & Mol. Wt. & Mol. Formula & Peak Area (\%) \\
\hline 13 & 43.98 & 9,11 Octadecadienoic acid butyl ester & 336.55 & & Structure \\
15 & 44.081 & Isooctyl phthalate & &
\end{tabular}

Table 2. GC-MS analysis of CLE-CuONPs.

\begin{tabular}{|c|c|c|c|c|c|c|}
\hline Peaks (P) & Retention Time (RT) & Name of Compound & Mol. Wt. & Mol. Formula & Peak Area (\%) & Structure \\
\hline 1 & 29.295 & Dipropyleneglicol diacrylate & 242.26 & $\mathrm{C}_{12} \mathrm{H}_{18} \mathrm{O}_{5}$ & 62.315 & \\
\hline 2 & 44.079 & $\alpha$-Monoolein & 356.53 & $\mathrm{C}_{21} \mathrm{H}_{40} \mathrm{O}_{4}$ & 37.685 & \\
\hline 3 & 44.953 & Isooctyl phthalate & 390.55 & $\mathrm{C}_{24} \mathrm{H}_{38} \mathrm{O}_{4}$ & 10.578 & \\
\hline
\end{tabular}




\subsection{Antibacterial Effects of CLE-CuONPS}

\subsubsection{Antibacterial Activity, MIC and MBC Determination}

Histograms shown in Figure 5A demonstrate a dose dependent reduction in the growth of clinical isolates. E. coli-336 showed increase in the zone of inhibition, measured as $12.0 \pm 0.5$ to $20.25 \pm 0.6 \mathrm{~mm}$ at 500 to $2000 \mu \mathrm{g} / \mathrm{mL}$ of CLE-CuONPs (Figure 5A,B). The observed changes are in line with antibacterial effects of green synthesized CuONPs against E. coli cells [46]. Comparatively, MSSA-2 showed a higher zone of inhibition measured as $10.7 \pm 0.8$ to $18.25 \pm 0.7 \mathrm{~mm}$, while MRSA- 1 showed $9.2 \pm 1.0$ to $16.2 \pm 0.5 \mathrm{~mm}$ zone of inhibition after exposure to CLE-CuONPs (500 to $2000 \mu \mathrm{g} / \mathrm{mL}$ ) (Figure 5A,B). CLE-alone diluted to 1:100 (v/v) has produced non-impressive cytotoxic effects (Figure 5B(I-III)). The antibacterial activities of CLE-CuONPs tested against the clinical isolates can be hierarchized as E. coli-336 > MSSA-2 > MRSA-1. Moreover, a similar trend of antibacterial effects was observed while determining the MIC and MBC of CLE-CuONPs against the test strains (Table 3). The MIC and MBC values of CLE-CuONPs against E. coli-336 were found to be 500 and $1500 \mu \mathrm{g} / \mathrm{mL}$. MSSA-2 showed the MIC and MBC at 1000 and $2000 \mu \mathrm{g} / \mathrm{mL}$, while 1500 and $2500 \mu \mathrm{g} / \mathrm{mL}$ of CLE-CuONPs were found to be effective as MIC and MBC in MRSA-1 (Table 3). Overall, our data on the antimicrobial effects of CLE-CuONPs supported well with the inherent properties of copper based antimicrobial formulations against MDR superbug MRSA [47].

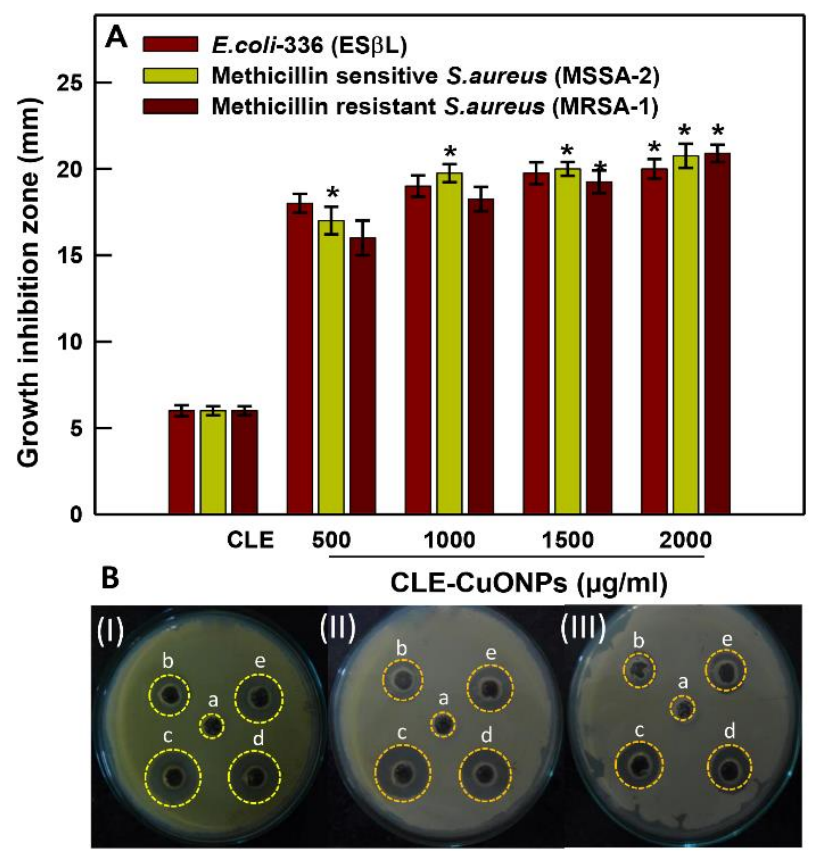

Figure 5. Antibacterial activity assessment. (A) shows assessment of antibacterial activity of CLE alone and CLE-CuONPs by a well diffusion assay. A volume of $100 \mu \mathrm{L}$ CLE (10\%) was taken as control. Each histogram represents the mean \pm SD of two independent experiments done in triplicate; (B) representative culture plates of (i) Gram-negative ES $\beta L$ producing E. coli-336, (ii) Gram-positive methicillin-sensitive MSSA-2, and (iii) and methicillin-resistant MRSA-1 exhibiting zone of growth inhibition at (a) 10\% CLE, and (b) 500, (c) 1000, (d) 1500 and, (e) $2000 \mu \mathrm{g} / \mathrm{mL}$ of CLE-CuONPs after $24 \mathrm{~h}$ of exposure. 
Table 3. MIC and MBC of clinical isolates exposed to CuONPs.

\begin{tabular}{ccc}
\hline \multirow{2}{*}{ Bacterial Strain } & \multicolumn{2}{c}{ CLE-CuONPs $(\mu \mathrm{g} / \mathrm{mL})$} \\
& MIC & MBC \\
\hline E. coli $($ ES $\beta L)-336$ & 500 & 1500 \\
S. aureus (MSSA-2) & 1000 & 2000 \\
S. aureus (MRSA-1) & 1500 & 2500 \\
\hline
\end{tabular}

\subsubsection{Comparative Planktonic Growth Inhibition Assessment}

A dose and time dependent reduction in the proliferative yield $\left(\mathrm{OD}_{620 \mathrm{~nm}}\right)$ of E. coli-336, MSSA-2, and MRSA-1 was recorded (Figure 6A-C). E. coli-336 cells after $10 \mathrm{~h}$ incubation with CLE-CuONPs $(250-2000 \mu \mathrm{g} / \mathrm{mL})$ showed $\mathrm{OD}_{620 \mathrm{~nm}}$ in the range of 0.47 to 0.19 , which are significantly lesser than the $\mathrm{OD}_{620 \mathrm{~nm}}$ of 0.53 recorded for the untreated control (Figure 6A).
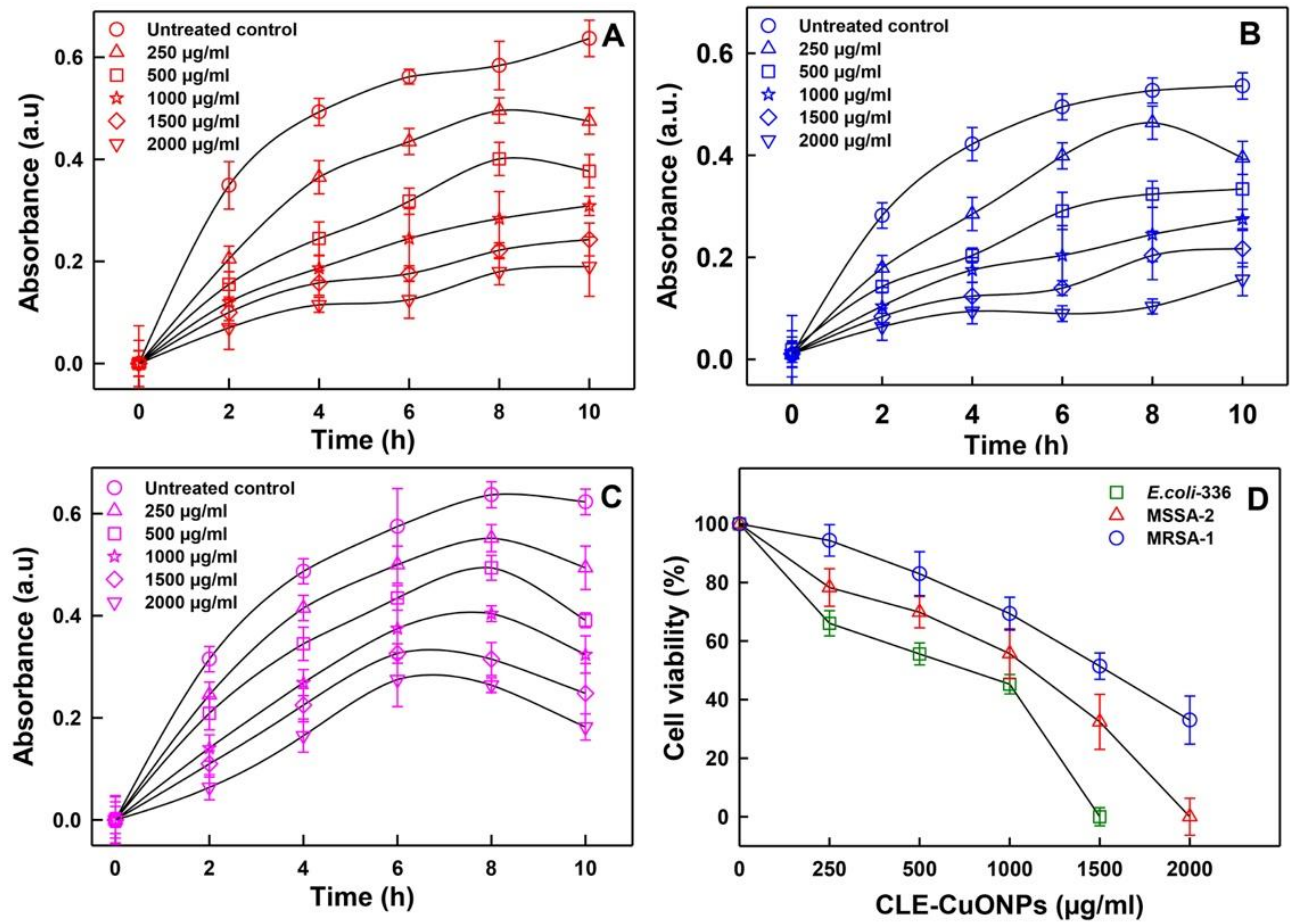

Figure 6. Antibacterial activity of CLE-CuONPs against MDR bacterial growth. Changes in the absorbance $\left(\mathrm{OD}_{620 \mathrm{~nm}}\right)$ of clinical bacterial isolates at increasing CLE-CuONPs concentrations (A-C). (A) Gram-negative ES $\beta L$ producing E. coli-336; (B) Gram-positive methicillin-sensitive MSSA-2, and (C) methicillin-resistant MRSA-1; (D) shows reduction in percent cell viability of clinical isolates treated with 250, 500, 1000, 1500 and $2000 \mu \mathrm{g} / \mathrm{mL}$ of CLE-CuONPs.

CLE-CuONPs also affected the growth of MSSA-2 and MRSA-1. Changes in the OD $620 \mathrm{~nm}$ values recorded between 0.39 to 0.15 , and 0.49 to 0.18 , as compared to the values of 0.53 and 0.62 in untreated controls (Figure 6B,C). Furthermore, the antibacterial effect of CLE-CuONPs suspensions (250-2000 $\mu \mathrm{g} / \mathrm{mL})$ on the percent survival of E. coli-336, MSSA-2 and MRSA-1 were estimated after $24 \mathrm{~h}$ of exposure. Figure 6D exhibits an apparent decline in the percent survival of E. coli-336 to $45.27 \pm 3.3 \%$ at $1000 \mu \mathrm{g} / \mathrm{mL}$ of CLE-CuONPs, whereas, E. coli-336 exposed to MBC $(1500 \mu \mathrm{g} / \mathrm{mL})$, its survival was reduced to zero. MSSA-2 and MRSA-1 at the sub-lethal concentration $(1500 \mu \mathrm{g} / \mathrm{mL})$ of CLE-CuONPs exhibited $32.41 \pm 9.4 \%$ and $51.4 \pm 4.5 \%$ survival. At $2000 \mu \mathrm{g} / \mathrm{mL}$, MSSA-2 survival decreased by almost $99.9 \%$ signifying its MBC value. At the same concentration, MRSA-1 survival declined to $33.0 \pm 8.2 \%$. The growth inhibitory results support the identical patterns of toxicity against E. coli-336 > MSSA-2 > MRSA-1, which is evident with well diffusion data above. CLE-CuONPS 
maximal toxicity to E. coli-336 can be related to its less rigid cell wall, containing 3 to 20 fold less peptidoglycans in Gram negative bacteria [48]. The difference in susceptibilities among the MSSA-2 and MRSA-1 was possibly due to the differences in their cell physiology, metabolism, and the microenvironment which renders the degree surface contact between NPs and the bacteria [9]. In order to validate the CLE-CuONPs induced antibacterial activities, the degree of cellular damage was compared directly with the treated and untreated bacterial cells under SEM. E. coli-336 cells showed cellular damage and loss of the native rod shape structure (Figure 7A,B). Similarly, CLE-CuONPs treated MRSA-1 cells show pits and cavities formation. The native spherical shape was also lost by the interaction between NPs and the bacterial cells (Figure 7C,D).
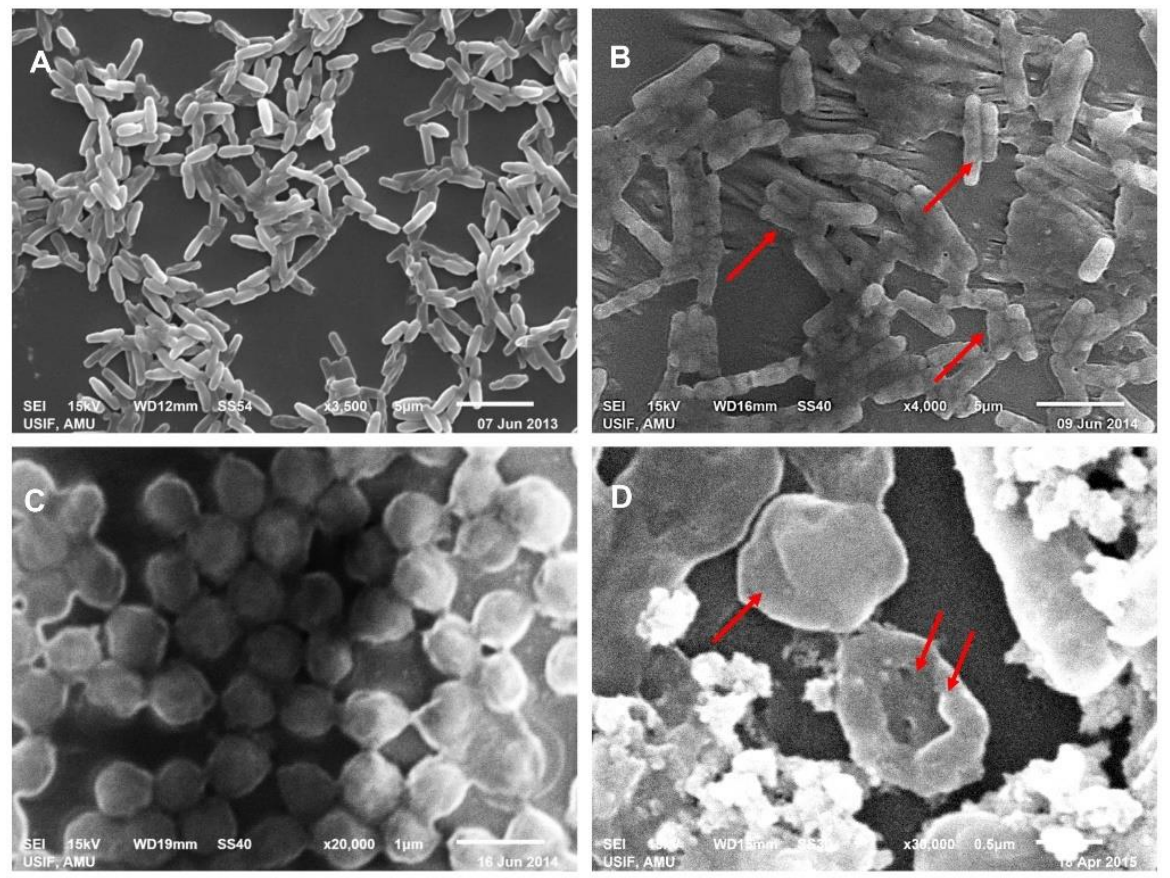

Figure 7. Ultrastructural analysis showing interaction of CLE-CuONPs with bacterial cells. Representative SEM images showing the cellular damage and surface binding of CLE-CuONPs with (B) E. coli-336 and (D) MRSA-1. The images in (A,C) show the untreated controls of E. coli-336, and MRSA-1.

\subsubsection{CLE-CuONPs Internalization in Bacterial Cells}

The AAS results revealed $22.80 \pm 2.6 \%, 19.2 \pm 4.2 \%$, and $16.2 \pm 3.6 \%$ accumulation of intracellular $\mathrm{Cu}^{2+}$ in E. coli-336, MSSA-2 and MRSA-1 when exposed to CLE-CuONPs (1000 $\left.\mu \mathrm{g} / \mathrm{mL}\right)$ (Figure 8A). The order of intracellular $\mathrm{Cu}^{2+}$ accumulation determined as E. coli-336 > MSSA-2 > MRSA-1. These differences primarily relate to the structural differences between the cell wall of Gram-positive and Gram-negative bacteria. Some auxiliary factors like bacterial growth rate, expression of stress-response genes, and stability of NPs at different $\mathrm{pH}$ play a crucial role. In addition, the enzymatic degradation within biofilm matrix, NPs electrostatic properties, corona formation, and metal dissolution play a viable role in evaluating the sensitivity or resistance against NPs [9]. TEM analysis of CLE-CuONPs treated E. coli-336 and MRSA-1 cells clearly demonstrate a significant amount of NPs internalization (Figure 8B). However, bacterial cells are not known to possess endocytosis mechanism to uptake extracellular entities. Therefore, CLE-CuONPs can be speculated to enter the cells by causing damage in the intact cell membrane, which may lead to the cytoplasmic leakage [49]. 
A

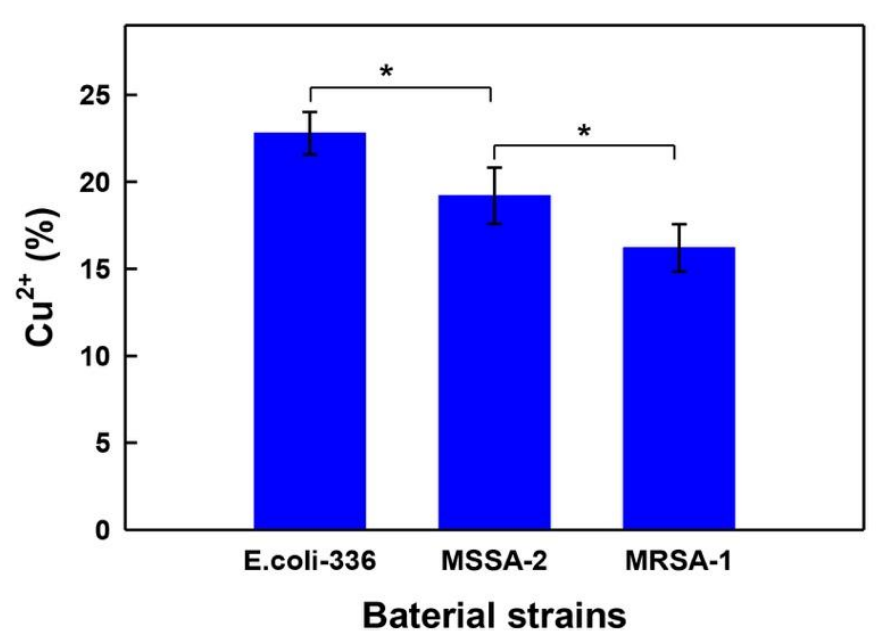

B CLE-CuONPs $(\mu \mathrm{g} / \mathrm{ml})$

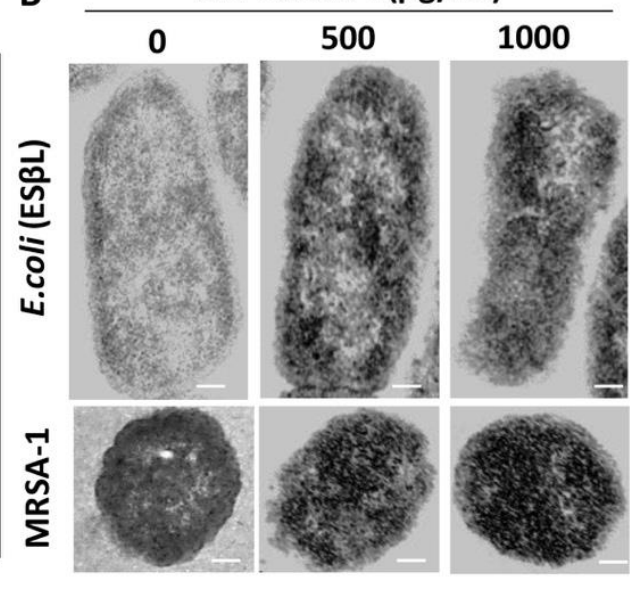

Figure 8. AAS detection of intracellular accumulation of $\mathrm{Cu}^{2+}$. (A) shows intracellular accumulation of $\mathrm{Cu}^{2+}$ in E. coli-336, MSSA-2 and MRSA-1. Asterisks represent significance at $p<0.05$, while error bars represent SD of triplicate samples; (B) demonstrate the TEM micrographs of E. coli-336 and MRSA-1 exposed to CLE-CuONPs (500-1000 $\mu \mathrm{g} / \mathrm{mL}$ ) indicating the intracellular NPs accumulation, and cellular damage. Scale bar $=200 \mathrm{~nm}$.

\subsection{Inhibition in Biofilm Formation}

A concentration depended biofilm inhibition was recorded against the planktonic growth of cells. Compared to the untreated control (100\% biofilm formation), E. coli-336 exposure with CLE-CuONPs suspensions ( 250 to $2000 \mu \mathrm{g} / \mathrm{mL}$ ) established $80.0 \pm 2.0$ to $33.0 \pm 3.2 \%$ biofilm formation on the bare surface of micro-wells (Figure 9A). Under the identical conditions, MRSA-1 shows $90.0 \pm 2.5$ to $49.0 \pm 3.1 \%$ biofilm formation. CLE-CuONPs exhibit more effective antibiofilm activity against $E$. coli-336. The observed trend is in line with the greater antibacterial effects against Gram negative isolate, as compared to the Gram positive bacterial isolates. These antibacterial activities are in good agreement with the previously reported antibacterial efficacy of CuONPs [9]. The qualitative CLSM data on biofilm density (Figure 9B) correspond well with the quantitative data (Figure 9A). Increasing concentrations of CLE-CuONPs reduces the biofilm formation in E. coli-336 and MRSA-1, as compared to the control cells. A possible explanation of the observed effects can be surmised with the size dependent dissolution of CuONPs, and subsequent release of $\mathrm{Cu}^{2+}$ in the microenvironment of bacterial cells. The dissolution of $\mathrm{Cu}^{2+}$ in the cytoplasm after internalization NPs may assist the biomolecular interaction of $\mathrm{Cu}^{2+}$ with DNA. These events may trigger the repeated redox reaction chain to generate reactive oxygen species leading to the membrane damage and bacterial cell death by oxidative stress [50]. 

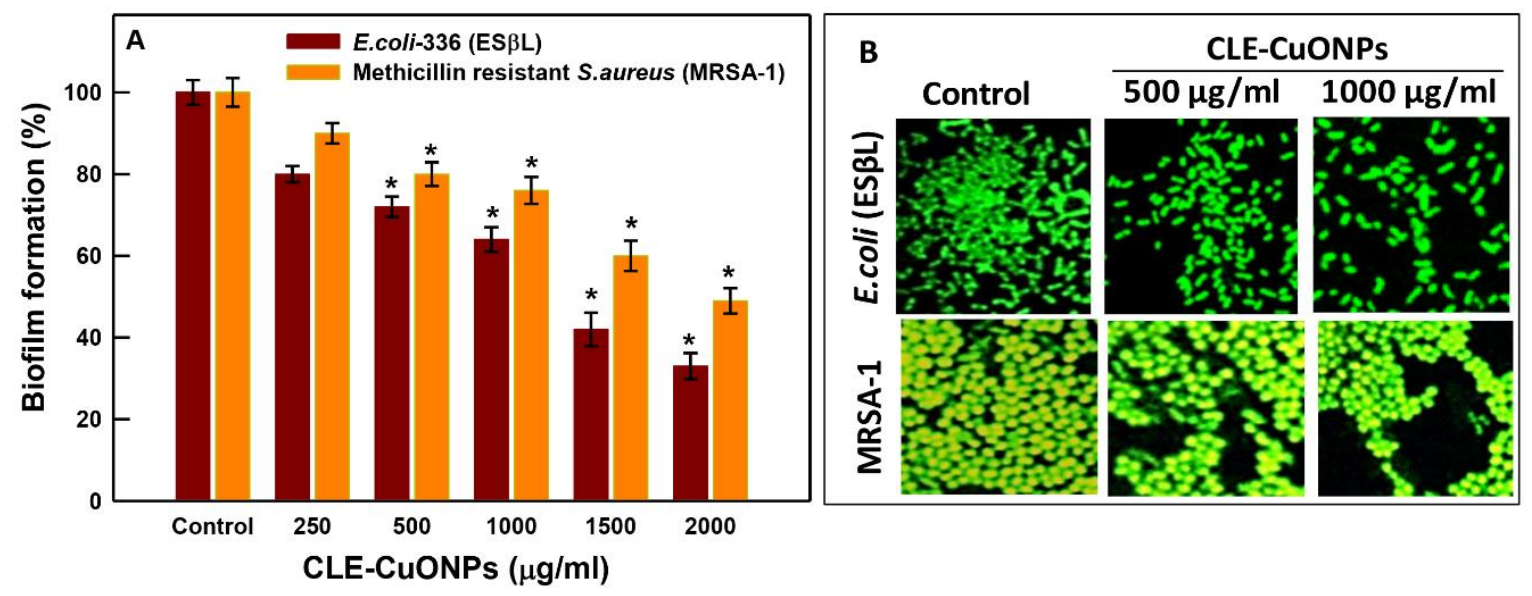

Figure 9. CLE-CuONPs induced antibiofilm activities in clinical isolates. (A) quantitative estimation of CLE-CuONPs showing inhibition of bacterial biofilm formation. The error bars represent mean \pm SD of two independent experiments done in triplicates. ${ }^{*} p<0.05$ vs. control; (B) qualitative analysis showing reduction in the biofilm formation by clinical isolates after CLE-CuONPs exposure analyzed by CLSM.

\section{Conclusions}

This study demonstrates a simple, eco-friendly biosynthesis method of esters functionalized CLE-CuONPs using an aqueous extract of CLE leaves. Comparative GC-MS analysis of CLE-alone and CLE-CuONPs provides substantial evidence that the CLE esters such as di-propyleneglicol diacrylate, $\alpha$-monoolein, and iso-octyl phthalate played a crucial role in $\mathrm{Cu}^{2+}$ or $\mathrm{Cu}^{3+}$ reduction, and surface functionalization. Comparative FTIR analyses reflect the spectral signature of auxiliary bio-actives of CLE such as proteins, sugars and polyphenols in association of CuONPs. Importantly, this study also shed light on the bio-actives esters as an efficient reducing, capping, and stabilizing agents at varying $\mathrm{pH}$ conditions (4.0 to 12.0). Particularly, under the harsh environmental $\mathrm{pH}$, the CLE-CuONPs can be speculated to act as a stable antimicrobial agent. A significant interaction and intracellular uptake of CLE-CuONPs in biofilm producing E. coli-336 and MSRA-1 was validated. CLSM results demonstrate the greater antibiofilm activities in E. coli followed by S. aureus owing to the differences in the cell wall compositions. Overall, our data unequivocally indicate that CLE-CuONPs may be utilized as a safer alternative against prominent MDR and biofilm infections in the biomedical settings.

Supplementary Materials: The following are available online at http://www.mdpi.com/2218-273X/10/2/169/s1, Table S1: FTIR analysis of CLE and CLE-CuONPs.

Author Contributions: Conceptualization, T.C., Q.S. and J.M.; Data curation, T.C., K.A. and Q.S.; Formal analysis, T.C., K.A., M.F. and R.W.; Investigation, T.C., Q.S., M.F. and J.M.; Methodology, T.C., K.A., M.F. and R.W.; Project administration, J.M.; Resources, J.M.; Supervision, J.M.; Validation, T.C.; Writing-original draft, T.C., K.A. and Q.S.; Writing-review and editing, M.F., R.W. and J.M. All authors have read and agreed to the published version of the manuscript.

Funding: The authors extend their appreciation to the Deanship of Scientific Research at King Saud University for funding this work through research group number (RG-1440-015).

Conflicts of Interest: The authors declare no conflict of interest.

\section{References}

1. Roy, A.; Bulut, O.; Some, S.; Mandal, A.K.; Yilmaz, M.D. Green synthesis of silver nanoparticles: Biomolecule-nanoparticle organizations targeting antimicrobial activity. RSC Adv. 2019, 9, 2673-2702. [CrossRef]

2. Yang, X.; Yang, M.; Pang, B.; Vara, M.; Xia, Y. Gold nanomaterials at work in biomedicine. Chem. Rev. 2015, 115, 10410-10488. [CrossRef] [PubMed]

3. Grimaldi, N.; Andrade, F.; Segovia, N.; Ferrer-Tasies, L.; Sala, S.; Veciana, J.; Ventosa, N. Lipid-based nanovesicles for nanomedicine. Chem. Soc. Rev. 2016, 45, 6520-6545. [CrossRef] [PubMed] 
4. Cui, J.; Richardson, J.J.; Bjoörnmalm, M.; Faria, M.; Caruso, F. Nanoengineered templated polymer particles: Navigating the biological realm. Acc. Chem. Res. 2016, 49, 1139-1148. [CrossRef] [PubMed]

5. Pelaz, B.; Alexiou, C.; Alvarez-Puebla, R.A.; Alves, F.; Andrews, A.M.; Ashraf, S.; Balogh, L.P.; Ballerini, L.; Bestetti, A.; Brendel, C. Diverse applications of nanomedicine; ACS Publications: Washington, DC, USA, 2017.

6. Jha, A.K.; Prasad, K.; Prasad, K.; Kulkarni, A. Plant system: Nature's nanofactory. Colloids Surf. B. Biointerfaces 2009, 73, 219-223. [CrossRef] [PubMed]

7. Park, Y.; Hong, Y.; Weyers, A.; Kim, Y.; Linhardt, R. Polysaccharides and phytochemicals: A natural reservoir for the green synthesis of gold and silver nanoparticles. IET Nanobiotechnology 2011, 5, 69-78. [CrossRef]

8. Mittal, A.K.; Chisti, Y.; Banerjee, U.C. Synthesis of metallic nanoparticles using plant extracts. Biotechnol. Adv. 2013, 31, 346-356. [CrossRef]

9. Ali, K.; Ahmed, B.; Ansari, S.M.; Saquib, Q.; Al-Khedhairy, A.A.; Dwivedi, S.; Alshaeri, M.; Khan, M.S.; Musarrat, J. Comparative in situ ROS mediated killing of bacteria with bulk analogue, Eucalyptus leaf extract (ELE)-capped and bare surface copper oxide nanoparticles. Mater. Sci. Eng. C Mater. Biol. Appl. 2019, 100, 747-758. [CrossRef]

10. Cherian, T.; Ali, K.; Fatima, S.; Saquib, Q.; Ansari, S.M.; Alwathnani, H.A.; Al-Khedhairy, A.A.; Al-Shaeri, M.; Musarrat, J. Myristica fragrans bio-active ester functionalized $\mathrm{ZnO}$ nanoparticles exhibit antibacterial and antibiofilm activities in clinical isolates. J. Microbiol. Methods 2019, 166, 105716. [CrossRef]

11. Vijaya Kumar, R.; Elgamiel, R.; Diamant, Y.; Gedanken, A.; Norwig, J. Sonochemical preparation and characterization of nanocrystalline copper oxide embedded in poly (vinyl alcohol) and its effect on crystal growth of copper oxide. Langmuir 2001, 17, 1406-1410. [CrossRef]

12. Debbichi, L.; Marco de Lucas, M.; Pierson, J.; Kruger, P. Vibrational properties of $\mathrm{CuO}$ and $\mathrm{Cu}_{4} \mathrm{O}_{3}$ from first-principles calculations, and Raman and infrared spectroscopy. J. Phys. Chem. C 2012, 116, 10232-10237. [CrossRef]

13. Sharma, J.K.; Akhtar, M.S.; Ameen, S.; Srivastava, P.; Singh, G. Green synthesis of CuO nanoparticles with leaf extract of Calotropis gigantea and its dye-sensitized solar cells applications. J. Alloy. Compd. 2015, 632, 321-325. [CrossRef]

14. Duman, F.; Ocsoy, I.; Kup, F.O. Chamomile flower extract-directed CuO nanoparticle formation for its antioxidant and DNA cleavage properties. Mater. Sci. Eng. C 2016, 60, 333-338. [CrossRef] [PubMed]

15. Wang, F.; Li, H.; Yuan, Z.; Sun, Y.; Chang, F.; Deng, H.; Xie, L.; Li, H. A highly sensitive gas sensor based on $\mathrm{CuO}$ nanoparticles synthetized via a sol-gel method. RSC Adv. 2016, 6, 79343-79349. [CrossRef]

16. Naika, H.R.; Lingaraju, K.; Manjunath, K.; Kumar, D.; Nagaraju, G.; Suresh, D.; Nagabhushana, H. Green synthesis of $\mathrm{CuO}$ nanoparticles using Gloriosa superba L. extract and their antibacterial activity. J. Taibah Univ. Sci. 2015, 9, 7-12. [CrossRef]

17. Sutradhar, P.; Saha, M.; Maiti, D. Microwave synthesis of copper oxide nanoparticles using tea leaf and coffee powder extracts and its antibacterial activity. J. Nanostructure Chem. 2014, 4, 86. [CrossRef]

18. Borkow, G.; Gabbay, J. Copper, an ancient remedy returning to fight microbial, fungal and viral infections. Curr. Chem. Biol. 2009, 3, 272-278.

19. Prakash, S.; Elavarasan, N.; Venkatesan, A.; Subashini, K.; Sowndharya, M.; Sujatha, V. Green synthesis of copper oxide nanoparticles and its effective applications in Biginelli reaction, BTB photodegradation and antibacterial activity. Adv. Powder Technol. 2018, 29, 3315-3326. [CrossRef]

20. Gangaprasad, D.; Raj, J.P.; Kiranmye, T.; Sadik, S.S.; Elangovan, J. A new paradigm of copper oxide nanoparticles catalyzed reactions: Synthesis of 1, 2, 3-triazoles through oxidative azide-olefin cycloaddition. RSC Adv. 2015, 5, 63473-63477. [CrossRef]

21. Nasrollahzadeh, M.; Sajadi, S.M.; Rostami-Vartooni, A.; Azarian, A. Palladium nanoparticles supported on copper oxide as an efficient and recyclable catalyst for carbon(sp2)-carbon(sp2) cross-coupling reaction. Mater. Res. Bull. 2015, 68, 150-154. [CrossRef]

22. Shahsavani, E.; Feizi, N.; Dehno Khalaji, A. Copper Oxide Nanoparticles Prepared by Solid State Thermal Decomposition: Synthesis and Characterization. J. Ultrafine Grained Nanostructured Mater. 2016, 49, 48-50. [CrossRef]

23. Luna, I.Z.; Hilary, L.N.; Chowdhury, A.S.; Gafur, M.; Khan, N.; Khan, R.A. Preparation and characterization of copper oxide nanoparticles synthesized via chemical precipitation method. Open Access Libr. J. 2015, 2, 1. [CrossRef] 
24. Lee, A.H.; Nikraz, H. BOD: COD ratio as an indicator for river pollution. Int. Proc. Chem. Biol. Environ. Eng. 2015, 88, 89-94.

25. Suleiman, M.; Mousa, M.; Hussein, A.; Hammouti, B.; Hadda, T.B.; Warad, I. Copper (II)-oxide nanostructures: Synthesis, characterizations and their applications-review. J. Mater. Environ. Sci. 2013, 4, 792-797.

26. Akhila, A. Essential Oil-Bearing Grasses: The Genus Cymbopogon; CRC Press: Boca Raton, FL, USA, 2009.

27. Ajayi, E.; Afolayan, A. Green synthesis, characterization and biological activities of silver nanoparticles from alkalinized Cymbopogon citratus Stapf. Adv. Nat. Sci. Nanosci. Nanotechnol. 2017, 8, 015017. [CrossRef]

28. Murugan, K.; Benelli, G.; Panneerselvam, C.; Subramaniam, J.; Jeyalalitha, T.; Dinesh, D.; Nicoletti, M.; Hwang, J.-S.; Suresh, U.; Madhiyazhagan, P. Cymbopogon citratus-synthesized gold nanoparticles boost the predation efficiency of copepod Mesocyclops aspericornis against malaria and dengue mosquitoes. Exp. Parasitol. 2015, 153, 129-138. [CrossRef]

29. Brumbaugh, A.D.; Cohen, K.A.; St. Angelo, S.K. Ultrasmall copper nanoparticles synthesized with a plant tea reducing agent. ACS Sustain. Chem. Eng. 2014, 2, 1933-1939. [CrossRef]

30. Maensiri, S.; Labuayai, S.; Laokul, P.; Klinkaewnarong, J.; Swatsitang, E. Structure and optical properties of $\mathrm{CeO}_{2}$ nanoparticles prepared by using lemongrass plant extract solution. Jpn. J. Appl. Phys. 2014, 53, 06JG14. [CrossRef]

31. Ali, K.; Ahmed, B.; Dwivedi, S.; Saquib, Q.; Al-Khedhairy, A.A.; Musarrat, J. Microwave Accelerated Green Synthesis of Stable Silver Nanoparticles with Eucalyptus globulus Leaf Extract and Their Antibacterial and Antibiofilm Activity on Clinical Isolates. PLOS ONE 2015, 10, e0131178. [CrossRef]

32. Desarkar, H.; Kumbhakar, P.; Mitra, A. Effect of ablation time and laser fluence on the optical properties of copper nano colloids prepared by laser ablation technique. Appl. Nanosci. 2012, 2, 285-291. [CrossRef]

33. Zain, N.M.; Stapley, A.G.F.; Shama, G. Green synthesis of silver and copper nanoparticles using ascorbic acid and chitosan for antimicrobial applications. Carbohydr. Polym. 2014, 112, 195-202. [CrossRef] [PubMed]

34. Kato, H.; Suzuki, M.; Fujita, K.; Horie, M.; Endoh, S.; Yoshida, Y.; Iwahashi, H.; Takahashi, K.; Nakamura, A.; Kinugasa, S. Reliable size determination of nanoparticles using dynamic light scattering method for in vitro toxicology assessment. Toxicol. Vitro 2009, 23, 927-934. [CrossRef] [PubMed]

35. Gunawan, C.; Teoh, W.Y.; Marquis, C.P.; Amal, R. Cytotoxic origin of copper (II) oxide nanoparticles: Comparative studies with micron-sized particles, leachate, and metal salts. ACS Nano 2011, 5, 7214-7225. [CrossRef] [PubMed]

36. Eltarahony, M.; Zaki, S.; Abd-El-Haleem, D. Concurrent synthesis of zero-and one-dimensional, spherical, rod-, needle-, and wire-shaped CuO nanoparticles by Proteus mirabilis 10B. J. Nanomater. 2018, 2018, 1849616. [CrossRef]

37. Nikam, A.V.; Arulkashmir, A.; Krishnamoorthy, K.; Kulkarni, A.A.; Prasad, B. pH-dependent single-step rapid synthesis of $\mathrm{CuO}$ and $\mathrm{Cu}_{2} \mathrm{O}$ nanoparticles from the same precursor. Cryst. Growth Des. 2014, 14, 4329-4334. [CrossRef]

38. Thekkae Padil, V.V.; Cernik, M. Green synthesis of copper oxide nanoparticles using gum karaya as a biotemplate and their antibacterial application. Int. J. Nanomed. 2013, 8, 889-898. [CrossRef]

39. Narasaiah, P.; Mandal, B.K.; Sarada, N. Biosynthesis of copper oxide nanoparticles from Drypetes sepiaria leaf extract and their catalytic activity to dye degradation. In Proceedings of the Materials Science and Engineering Conference Series, Beijing, China, 24-27 October 2017; p. 022012.

40. Kumari, M.M.; Jacob, J.; Philip, D. Green synthesis and applications of Au-Ag bimetallic nanoparticles. Spectrochim. Acta Part. A: Mol. Biomol. Spectrosc. 2015, 137, 185-192. [CrossRef]

41. Sankar, R.; Maheswari, R.; Karthik, S.; Shivashangari, K.S.; Ravikumar, V. Anticancer activity of Ficus religiosa engineered copper oxide nanoparticles. Mater. Sci. Eng. C 2014, 44, 234-239. [CrossRef]

42. Menezes Filho, A.; dos Santos, F.N.; Pereira, P.A.d.P. Development, validation and application of a method based on DI-SPME and GC-MS for determination of pesticides of different chemical groups in surface and groundwater samples. Microchem. J. 2010, 96, 139-145. [CrossRef]

43. Wei, X.; Koo, I.; Kim, S.; Zhang, X. Compound identification in GC-MS by simultaneously evaluating the mass spectrum and retention index. Analyst 2014, 139, 2507-2514. [CrossRef]

44. Uraku, A.J.; Onuoha, S.C.; Edwin, N.; Ezeani, N.; Ogbanshi, M.E.; Ezeali, C.; Nwali, B.U.; Ominyi, M.C. Nutritional and Anti-Nutritional Quantification Assessment of Cymbopopgon citratus Leaf. Pharmacol. Pharm. 2015, 6, 401. [CrossRef] 
45. Wei, Y.; Wang, J. Studies on the chemical constituents of hypogeal part from Limonium bicolor. Zhong Yao Cai 2006, 29, 1182-1184. [PubMed]

46. Sivaraj, R.; Rahman, P.K.; Rajiv, P.; Narendhran, S.; Venckatesh, R. Biosynthesis and characterization of Acalypha indica mediated copper oxide nanoparticles and evaluation of its antimicrobial and anticancer activity. Spectrochim. Acta Part A Mol. Biomol. Spectrosc. 2014, 129, 255-258. [CrossRef] [PubMed]

47. Weaver, L.; Noyce, J.; Michels, H.; Keevil, C. Potential action of copper surfaces on meticillin-resistant Staphylococcus aureus. J. Appl. Microbiol. 2010, 109, 2200-2205. [CrossRef]

48. Kawahara, K.; Tsuruda, K.; Morishita, M.; Uchida, M. Antibacterial effect of silver-zeolite on oral bacteria under anaerobic conditions. Dent. Mater. 2000, 16, 452-455. [CrossRef]

49. Jayawardena, H.S.N.; Jayawardana, K.W.; Chen, X.; Yan, M. Maltoheptaose promotes nanoparticle internalization by Escherichia coli. Chem. Commun. 2013, 49, 3034-3036. [CrossRef]

50. Applerot, G.; Lellouche, J.; Lipovsky, A.; Nitzan, Y.; Lubart, R.; Gedanken, A.; Banin, E. Understanding the antibacterial mechanism of $\mathrm{CuO}$ nanoparticles: Revealing the route of induced oxidative stress. Small 2012, 8, 3326-3337. [CrossRef]

(C) 2020 by the authors. Licensee MDPI, Basel, Switzerland. This article is an open access article distributed under the terms and conditions of the Creative Commons Attribution (CC BY) license (http://creativecommons.org/licenses/by/4.0/). 